\title{
Implementasi Model Prototype pada Sistem Informasi Pelayanan Donor pada Palang Merah Indonesia (PMI) Kota Pontianak Berbasis Mobile
}

\author{
Yoki Firmansyah $^{\mathrm{a} 1}$, Wanty Eka Jayantia ${ }^{\mathrm{a} 2}$, Muhammad Sony Maulana ${ }^{\mathrm{a} 3}$, Agung Sasongko ${ }^{\mathrm{a} 4}$, Indra Prasetya ${ }^{\mathrm{a} 5}$ \\ ${ }^{a}$ Fakultas Teknologi Informasi, Universitas Bina Sarana Informatika Kampus Kota Pontianak \\ Jalan Abdurraman Saleh No 18 A, Pontianak, Kalimantan Barat \\ ${ }^{1}$ yoki.yryebsi.ac.id \\ ${ }^{2}$ wanty.wejebsi.ac.id \\ ${ }^{3}$ muhammad. momebsi.ac.id \\ ${ }^{4}$ agung.ako@bsi.ac.id \\ 5indra.pras09@gmail. com
}

\begin{abstract}
Abstrak
Palang merah Indonesia (PMI) merupakan sebuah organisasi kemanusiaan salah satu unitnya adalah unit transfuse darah (UTD) sebagai pelayanan donor darah. Berdasarkan hasil observasi dan wawancara ditemukan beberapa permasalahan diantaranya yaitu prosedur pendaftaran pendonor masih cukup rumit, dengan mengisi formulir, dan para calon pendonor harus datang langsung ke tempat donor, selain itu cara yang lama atau belum terkomputerisasi masih ditemukan dan akhirnya menghambat pelayanan Donor, maka dari itu dalam penelitian ini dibuatlah sebuah sistem informasi pelayanan donor darah untuk mengatasi masalah tersebut. Adapun sistem informasi dibuat dengan menggunakan model Prototype yang terdiri dari beberapa tahapan seperti mendengarkan kebutuhan, perencanaan dan pembuatan mock up. Selain itu digunakan juda teknik pengumpulan data seperti observasi, wawancara dan studi pustaka. Kedepannya akan ada 3 user yang akan menggunakan sistem informasi ini yaitu admin, kepala unit dan pendonor, sistem informasi yang dibuat yaitu berbasis mobile yang dapat diinstal dan dijalankan di perangkat yang berbasis Android, dengan harapan dapat memudahkan para pendonor dalam mendapatkan layanan di Palang merah Indonesia (PMI).
\end{abstract}

Kata kunci: Pelayanan Donor, Model Prototype. Sistem Informasi , Palang Merah Indonesia.

\section{Implementation of the Prototype Model in the Mobile-Based Donor Service Information System at the Indonesian Red Cross (PMI) Pontianak}

\begin{abstract}
The Indonesian Red Cross (PMI) is a humanitarian organization. One of its units is the Blood Transfusion Unit (UTD) as a blood donor service. Based on the results of observations and interviews, several problems were found, including the procedure for registering donors is still quite complicated, by filling out forms, and prospective donors must come directly to the donor site, in addition to the old or not yet computerized methods are still found and ultimately hinder the service of donors. Therefore, in this study, an information system for blood donation services was created to overcome this problem. The information system is made using a prototype model which consists of several stages such as listening to needs, planning and making mock ups. In addition, data collection techniques such as observation, interviews and literature studies are also used. In the future there will be 3 users who will use this information system, namely admin, unit head and donors, the information system created is mobile-based that can be installed and run on Android-based devices, in the hope of making it easier for donors to get services at the Indonesian Red Cross. (PMI)
\end{abstract}

Keywords: Donor Service, Prototype Model, Information Systems, Indonesian Red Cross 


\section{PENDAhuluan}

Semakin berkembangnya bidang teknologi informasi, menuntut setiap instansi pemerintah untuk menerapkan teknologi informasi disetiap proses pekerjaannya[1]. Alas an menggunakan system informasi dalam mendukung proses pekerjaan adalah untuk mempermudah dan mempersingkat waktu pekerjaan yang biasanya dikerjakan harus memerlukan waktu yang cukup panjang menjadi lebih mudah dan lebih ringkas [1]. Salah satu instansi yang dapat menerapkan teknologi informasi dalam menjalankan pekerjaannya adalah Palang Merah Indonesia (PMI).

Palang Merah Indonesia (PMI) adalah sebuah organisasi perhimpunan nasional di Indonesia yang bergerak dalam bidang sosial kemanusiaan yang tidak memihak golongan politik, ras, suku ataupun agama tertentu. PMI sebagai salah satu organisasi sosial kemasyarakatan selalu berupaya meningkatkan peranannya dalam kegiatan sosial masyarakat seiring dengan pertumbuhan dan perkembangan masyarakat yang ada. [2].

PMI Kota Pontianak yang berlalamat di J1. Jenderal Ahmad Yani RW No.30, RW.RT.03, Benua Melayu Darat, Kec. Pontianak Selatan, Kota Pontianak, Kalimantan Barat 78113 adalah organisasi kemanusian yang merupakan bagian dari keluarga besar Palang Merah Indonesia. Sebagai organisasi kemanusiaan, PMI Pontianak Kota memiliki berbagai macam kegiatan, salah satunya adalah kegiatan donor darah yang dilakukan Unit Tranfusi Darah (UTD).

Berdasarkan hasil diskusi, observasi dan wawancara yang dilakukan sebelum penelitian dilaksanakan ditemukan beberapa permasalahan yang ada pada UTD PMI diantaranya yaitu pelayanan donor dan ketersediaan darah perlu mendapatkan peningkatan. Hal ini dikarenakan ditemukan cara cara konvensional yang masih dipergunakan, seperti masih menggunakan kertas, calon pendonor ataupun yang mencari darah harus dating ketempat, hingga masih mengisi form form yang dapat menghampat proses pelayanan. Melihat masalah tersebut maka dari itu dalam penelitian ini akan dibuat sebuah system informasi pelayanan donor darah.

sistem adalah suatu uraian pekerjaan dari sebuah prosedur yang saling berinteraktif atau berpadu untuk melakukan pekerjaan dengan tujuan yang telah ditentukan sebelumnya[3], dan Informasi merupakan data yang diolah menjadi sebuah bentuk yang lebih berguna dan lebih berarti bagi yang menerimanya [4], selait itu informasi juga dapat diartikan sebagai data yang terlah diorganisasi sehingga memiliki manfaat.[5].

jadi yang dimaksud dengan sistem informasi merupakan sebuah komponen dalam sebuah informasi yang saling berhubungan dengan proses penciptaan dan aliran informasi[6]. adapun sistem informasi yang dibangun menggunakan basiswa mobile Aplication. Mobil Application merupakan sebuah aplikasi yang dibuat untuk perangkat yang bergerak seperti smartphone, smartwatch, dan Tablet [7].

Selain berbasis mobile sistem informasi pelayanan donor ini juga menggunakan basis data. Basis data sendiri adalah kumpulan dari berbagai data dan informasi yang tersusun dan tersimpan secara sistematik [8] dan dalam penelitian ini dugunakan MySql, Mysql sendiri adalah sebuah software atau perangkat lunah yang dapat memanajemen basis data SQL [9]. Pada dasarnya Mysql ini sebenarnya adalah turunan yang berasal dari salah satu konsep utama dalam data base yang didalamnya mengandung bahasa SQL [10].

\section{Metodologi}

\section{A. Metode Pengembangan Perangkat Lunak}

Sistem Pelayanan Donor darah ini memanfaatkan Model Pengembangan Perangkat lunak Model Prototype. Model prototyping merupakan suatu teknik untuk mengumpulkan informasi tertentu mengenai kebutuhankebutuhan informasi pengguna secara cepat. Berfokus pada penyajian dari aspek-aspek perangkat lunak tersebut yang akan nampak bagi pelanggan atau pemakai. Prototipe tersebut akan dievaluasi oleh pelanggan/pemakai dan dipakai untuk menyaring kebutuhan pengembangan perangkat lunak[11]. sedangkan pendapat lain mengatakan prototyping merupakan metode pengembangan perangat lunak, yang berupa model fisik kerja sistem dan berfungsi sebagai versi awal dari sistem. Dengan metode prototyping ini akan dihasilkan prototype sistem sebagai perantara pengembang dan pengguna agar dapat berinteraksi dalam proses kegiatan pengembangan sistem informasi. Agar proses pembuatan prototype ini berhasil dengan baik adalah dengan mendefinisikan aturan-aturan pada tahap awal, yaitu pengembang dan penguna harus satu pemahaman bahwa prototype dibangun untuk mendefinisikan kebutuhan awal. Prototype akan dihilangkan atau ditambahkan pada bagiannya sehingga sesuai dengan perencanaan dan analisis yang dilakukan oleh pengembang sampai dengan ujicoba dilakukan secara simultan seiiring dengan proses pengembangan [12].

Model protoype ini memiliki beberapa tahapan [13], yaitu :

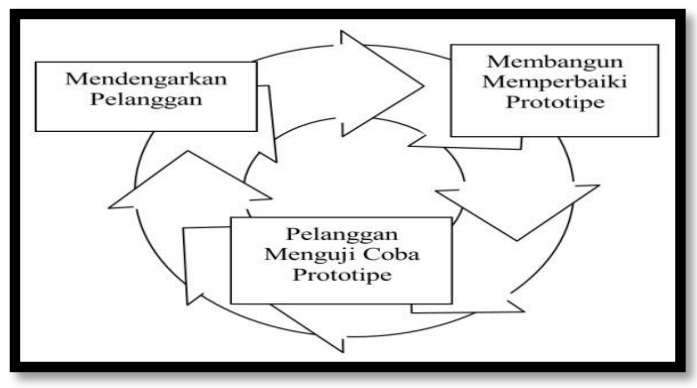

Sumber : Sukamto \& Shalahuddin, (2015) Gambar 1. Model prototype

1) Mendengarkan Pelanggan: Pada tahap ini dilakukan metode Pengumpulan data observasi dan wawancara dimana, dengan wawancara dan observasi ditemukan permasalahan yang selama ini terjadi pada objek penelitian, dimmana permasalahan utama dalam penelitian ini adalah terbatasnya tenaga dalam pengelolaan ketersediaan darah, lalu informasi kepada masyarakat juga tidak langsung sehingga terjadi missinformasi. Adapun wawancara dilakukan langsung dengan staff umum dan kepegawaian, dan observasi dilaksanakan langsung di Kantor PMI Kota Pontianak, selain itu dalam proses ini 
juga dianalisa prosedur sistem berjalan yang selama ini ada, dan nantinya dituangkan dalam bentuk diagram activity. Diagram activity merupakan sebuah diagram yang menggambahkan workflow atau aliran kerja dari sebuah proses bisnis. [14]

2) Membangun dan Memperbaiki Prototype: Mockup yang dimaksud merupakan sesuatu yang digunakan sebagai model desain yang digunakan untuk mengajar, demonstrasi dan evaluasi desain sistem. Mock-up akan disebut sebagai prototype apabila perangkat lunak tersebut menyediakan atau mampu mendemonstrasikan sebagian besar fungsi sistem perangkat lunak dan memungkinkan pengujian desain sistem perangkat lunak [15]. Adapun mock up dibuat dengan menggunakan aplikasi Figma.

3) Pelanggan Menguji Coba Prototipe: Setelah aplikasi dibangun, dan diperbaiki maka berikutnya adalah melakukan uji coba, dimana Sistem Informasi Indeks kepuasan masyarakat akan langsung diujicobakan oleh pelanggan, adapun metode pengujian yang digunakan adalah menggunakan metode blackbox testing, blackbox testing atau yang biasa disebut dengan pengujian kotak hitam dilakukan dengan membuat kasus uji yang bersifat mencoba semua fungsi dengan memakai perangkat lunak apakah sesuai dengan spesifikasi yang dibutuhkan[13] [16].

\section{B. Metode Pengumpulan Data}

Teknik pengumpulan data merupakan teknik yang paling bagus untuk digunakan dalam suatu penelitian karena melalui penelitian kita bisa mendapatkan data-data yang kita butuhkan[17]. Untuk mendapatkan data tersebut maka digunakan teknik pengumpulan data yang meliputi:

1) Wawancara: melakukan proses tanya jawab (Wawancara) secara kepada bapak Agung Wiratama selaku Staff Administrasi Umum dan Kepegawaian di PMI Kota Pontianak. Wawancara yang dilakukan kurang lebih 2 jam ini berfokus kepada untuk mendapatkan informasi seputar pelayanan PMI kepada msayarakat, dan dari wawancara inilah ditemukan permasalahan yang sudah di tuangkan di bagian latar belakang.

2) Proses Observasi: dilakukan dengan cara mengamati objek penelitian secara langsung, yaitu mendatangi PMI Kota Pontianak, observasi dilakukan pada unit Donor darah dengan tujuan untuk melihat secara langsung bagaimana pelayanan tentang pencatatan kesediaan darah selama ini dilakukan,

3) Studi Pustaka: Studi pustaka adalah salah satu metode yang digunakan dalam pengumpulan data. Yaitu dengan menganalisis buku dan dokumen yang ada di PMI dengan tujuan mendapatkan informasi terkait sistem informasi yang akan dibuat kedepannya.

\section{HASIL DAN PEMBAHASAN}

Hasil dari penelitian ini merupakan sebuah system informasi indeks kepuasan masyarakat yang dapat membantu Dinas Kependudukan dan Pencatatan sipil dalam menyelesaikan permasalahan permasalahan yang terjadi, yang berkaitan dengan survey indeks kepuasan masyarakat. Dan telah dibahas sebelumnya bahwa metode pengembangan perangkat lunak yang digunakan adalah model prototype, maka dari itu hasil dari penelitian ini juga akan mengikuti langkah langkah dari model tersebut.

Adapun penjelasan dari masing masing langkah yaitu sebagai berikut

\section{A. Mendengarkan Pelanggan}

1) Prosedur Sistem Berjalan: Prosedur sistem yang telah dianalisa bertujuan untuk sedang berjalan dilakukan menemukan urutan kejadian yang ada dan dapat dibuat dengan Activity Diagram. Adapun prosedur pelayanan donor darah pada Unit Donor Darah (UTD) PMI Kota Pontianak dijelaskan sebagai berikut :

a. Prosedur Donor Darah

Pendonor datang ke UTD/Mobil Unit untuk mengisi mengambil dan mengisi formulir yang telah disediakan, setelah itu pendonor menyerahkan formulir kepada petugas admininstrasi. Kemudian pendonor dipanggil keruangan khusus untuk dimintai konseling pra donor, pengecekan tensi, $\mathrm{Hb}$, suhu tubuh serta nadi oleh petugas seleksi donor. Jika memenuhi syarat, maka dilanjutkan dengan proses mencuci lengan yang bertujuan untuk meminimalkan kontaminasi bakteri kemudian dilanjutkan dengan peoses penyadapan oleh petugas. Penyadapan dilakukan oleh petugas yang profesional dibidangnya. Petugas memberikan label pada kantong dara pendonor dan mengambil sampel darahnya untuk diperiksa dilabolatorium. Terakhir, pendonor dipersilahkan istirahat dan menerima makanan ringan.

b. Prosedur Penyadapan Darah

Sebelum melakukan penyadapan/pengambilan darah oleh petugas, pendonor terlebih dahulu dipesilahkan mencuci tangan dengan sabun antiseptik lalu setelahnya dipersilahkan berbaring pada tempat tidur yang disediakan pada posisi terlentang dan tangan lurus kesamping menghadap keatas. Petugas akan memasangkan tensi meter ke lengan pendonor, kemudian petugas mengidentifikasi sampel darah yang dikirimkan dan harus sesuai dengan formulir donor darah. Jika sudah sesuai, maka petugas akan mulai melakukan penyadapan darah dan jika tidak maka proses penyadapan tidak akan dilanjutkan. Setelah proses penyadapan selesai, pendonor dipersilahkan keruangan istirahat.

c. Prosedur Permintaan Darah

Pada prosedur ini, yang menentukan pasien memerlukan darah adalah dokter yang menangani/merawat pasien. Dokter/Rumah Sakit mengirimkan surat permintaan darah beserta contoh darah dari pasien ke labolatorium UTD PMI Kota Pontianak. Atas permintaan tersebut, diadakan pemeriksaan reaksi silang antara contoh darah dengan contoh darah pasien yang memakan waktu kurang lebih 1-2 jam. Pemeriksaan ini mutlak harus dilakukan walaupun golongan darah pasient dengan golongan darah donor sama. Bila pada pemeriksaan silang tidak terdapat kelainan maka barulah darah donor diberikan kepada pasien. Bila pemeriksaan silang ditemukan 
kalainan atau ketidak cocokan perlu dilakukan pemeriksaan lanjutan untuk mencari sebab kelainan atau ketidakcocokan tersebut.

d. Prosedur Cek Stok Darah

Untuk mengecek stok darah, pengguna/masyarakat mengguna bisa mengakses website ayodonor.pmi.or.id kemudian masukan golongan darah, komponen darah serta provinsi, setelah itu tekan cari. Sistem akan menampilkan stok darah beserta alamat Unit Tranfusi Darah.

2) Diagram Activity Prosedur Sistem Berjalan : Berdasarkan dari prosedur sistem berjalan berikutnya dibuatlah diagram activity prosedur sistem berjalan agar dapat memudahkan dalam menemukan permasalahan.

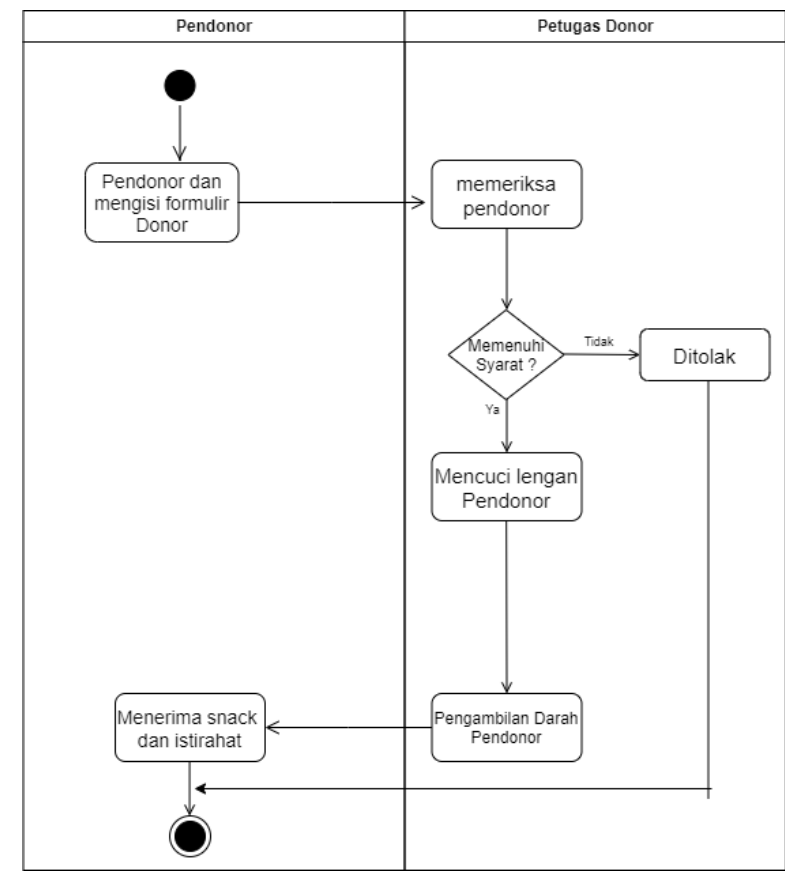

Sumber : Hasil observasi dan wawancara (2021) Gambar 2. Activity diagram donor darah

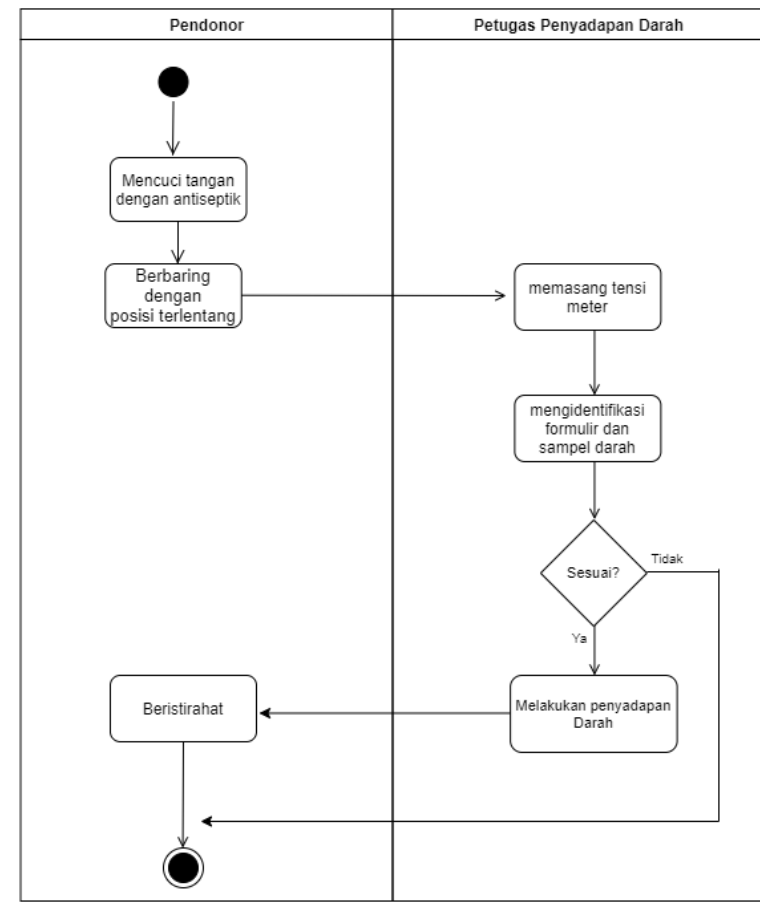

Sumber : Hasil observasi dan wawancara (2021)

Gambar 3. Activity diagram penyadapan darah

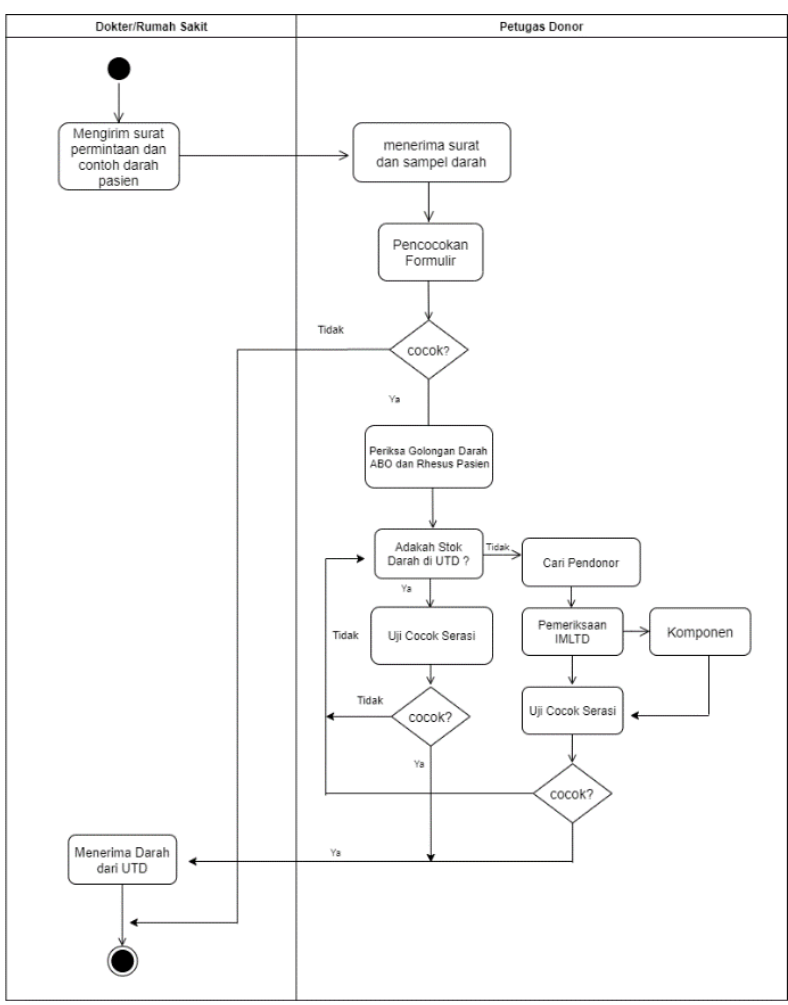

Sumber : Hasil observasi dan wawancara (2021) Gambar 4. Activity diagram perminataan darah 


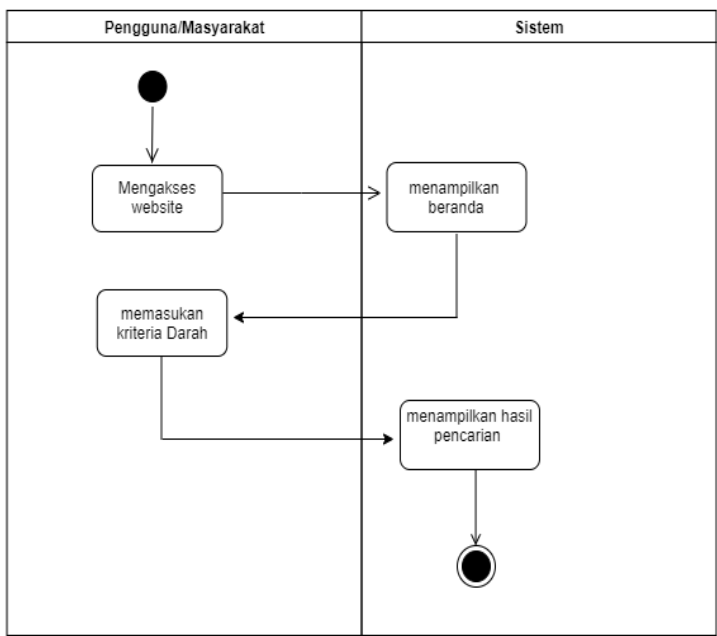

Sumber : Hasil observasi dan wawancara (2021)

Gambar 5. Activity diagram cek stok darah

3) Permasalahan Pokok: Dari pengamatan sistem pelayanan donor darah telah dilakukan pada Unit Tranfusi Darah (UTD) PMI Kota Pontianak, disimpulkan bahwa untuk pelayanan donor perlu ditingkatkan lagi karena masih menggunakan cara lama sehingga ini menimbulkan beberapa permasalahan. Adapun permasalahanya jabarkan sebagai berikut.

- Dalam proses registrasi, pendonor harus datang ketempat untuk mengisi formulir dan kuisioner kesehatan dalam bentuk kertas yang dapat menyebabkan penumpukan berkas.

- Sistem yang ada saat ini hanya diperuntukan untuk pihak instansi, hanya sebatas pencatatan dari lembar kertas yang diisi dari pendonor.

- Keterbatasan informasi mengenai stok darah yang dapat menyebabkan keterlambatan dalam penanganan pasien

- Belum adanya sistem yang dapat memberikan informsi tentang pengingat donor sehingga menyebabkan kurangnya kesadaran masyarakat dalam pentingnya donor darah.

- Belum adanya sistem khusus yang dibuat oleh Unit Tranfusi Darah PMI Kota Pontianak dalam pelayanan donor dan ketersediaan stok darah.

4) Pemecahan Masalah: Dalam mengatasi dan mengurangi permasalahan pada sistem pelayanan donor darah di Unit Tranfusi Darah PMI Kota Pontianak, diberikan solusi untuk memecahkan permasalahan tersebut yaitu :

- Perlu adanya sistem yang memungkinkan masyarakat untuk bisa melakukan pendaftaran donor darah secara online, sehingga masyarakat dapat menghemat waktu dan tidak perlu antri.

- Membuat sebuah sistem yang diperuntukan oleh pihak instansi dan juga masyarakat yang berguna sebagai interaksi seperti tanya jawab seputar donor darah dan lainnya.

- Pembuatan sistem yang dapat menampilkan stok ketersediaan darah secara real-time sehingga informasi yang dibutuhkan masyarakat tidak mengalami keterlambatan.
- Sistem yang akan dibuat nanti harusnya terdapat fitur pengingat donor yang dapat meningkatkan kesadaran masyarakat akan pentingnya donor darah.

- Perlu adanya sistem khusus yang dibuat oleh Unit Tranfusi Darah PMI Kota Pontianak yang dapat mengakomodasi segala bentuk pelayanan kepada masyarakat seperti pendaftaran sebagai pendonor darah secara online, pengingat donor, menampilkan informasi seputar donor, stok darah dan lain-lain.

5) Analisa Kebutuhan perangkat Lunak: Analisis kebutuhan merupakan analisa yang berkaitan dengan kebutuhan-kebutuhan yang diperlukan baik dari segi pengguna maupun dari segi sistem itu sendiri yang nantinya akan dijadikan sebagai dasar Perancangan Sistem Informasi donor darah. Yang menjelaskan tentang kebutuhan pengguna dan kebutuhan sistem., dan kebutuhan nya adalah sebagai berikut :

Sistem Informasi donor darah yaitu terdapat 3 user yang saling berhubungan pada satu sistem yaitu meliputi bagian staff administrasi, kepala unit, dan calon pendonor

Ketiga level user tersebut memiliki kebutuhan informasi yang berbeda-beda dan memiliki interaksi dengan sistem yang berbeda pula. Adapun beberapa kebutuhan informasi dan interaksi yang dimaksud adalah sebagai berikut:

a. Skenario Kebutuhan Staff Administrasi

- dapat melakukan Login, login dengan menggunakan username dan password agar dapat mengaksses aplikasi dan mengelola pengguna maupun pendonor.

- dapat input stok darah. Pada proses ini, admin yang ingin menambahkan stok darah (masuk ataupun keluar) dapat mengkases menu stok.

- dapat melihat permintaan darah. Terdapat menu permintaan yang berfungsi untuk melihat permintaan darah baik itu dari user maupun pendonor.

- dapat memberikan info donor, Info donor yang diberikan berupa waktu, tempat, waktu donor kepada pendonor.

- dapat melihat dan mencetak laporan donor Pada menu laporan dapat melihat serta mencetak laporan donor, hal ini dapat digunakan untuk pelaporan kepada Kepala Unit.

- dapat mengelola pengguna. dapat mengelola pengguna yang terdaftar pada aplikasi, proses kelola pengguna meliputi edit dan hapus.

b. Skenario Kebutuhan Pengguna

- Pengguna dapat melakukan membuat akun Sebelum dapat mengkases aplikasi, pengguna terlebih dahulu harus melalukan pembuatan akun.

- Pengguna dapat Login, Pengguna yang telah mendaftar dapat masuk ke aplikasi menggunakan email dan password.

- Pengguna dapat melihat stok darah, Dengan mengakses menu stok pengguna dapat melihat stok darah, untuk mencari kebutuhan darah secara mendetail, pengguna dapat menggunakan fitur cari stok. 
- Pengguna dapat mendaftar sebagai pendonor, Pengguna yang ingin menjadi penndonor dapat mendaftarkan diri sebagai pendonor dengan mengisi form pendaftaran.

- Pengguna dapat melihat informasi donor, Informasi yang pengguna peroleh berupa waktu, riwayat, total donor hingga tempat pelaksanaan kegiatan donor darah.

- $\quad$ pengguna dapat melihat riwayat donor, Pengguna yang telah pernah melakukan donor dapat melihat riwayat donor yang terdapat pada menu riwayat.

- pengguna dapat melakukan permintaan darah, Pendonor dapat melakukan permintaan darah dengan mengisi formulir permintaan darah serta mengupload surat keterangan permintaan darah dari dokter yang merawat pasien.

- Pengguna dapat mencetak bukti permintaan darah, Pendonor yang telah membuat permintaand darah dapat mencetak bukti permintaan darah guna sebagai bukti telah melakukan permintaan darah.

c. Skenario Kebutuhan Kepala Unit

- Kepala Unit dapat melakukan login Kepala unit dapat melakukan login dengan menggunakan username dan password untuk mengakses aplikasi.

- Kepala Unit dapat mengelola admin Kepala Unit dapat mengelola admin yang terdaftar pada aplikasi, proses kelola pengguna meliputi edit dan hapus.

- Kepala Unit dapat melihat dan mencetak laporan, Laporan yang dikelola oleh admin dapat dilihat juga oleh Kepala Unit.

\section{d. Diagram Use Case}

Rancangan sistem pelayanan donor dan ketersediaan darah ini nantinya akan dimodelkan ke dalam use case diagram, dan hasil dari pemodelan rancangan adalah sebagai berikut :

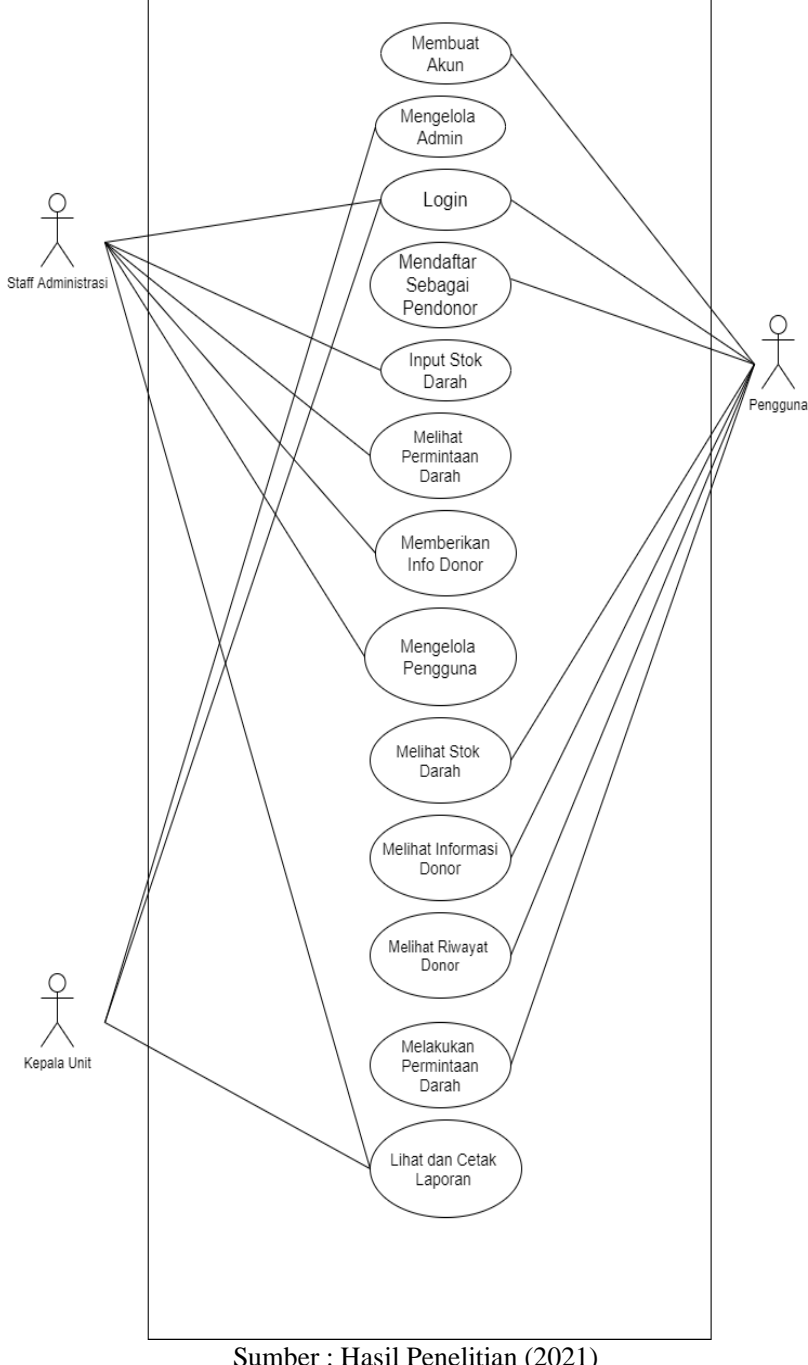

Gambar 6. Use case diagram usulan sistem pelayanan donor dan ketersedian darah

B. Membangun Prototype

1. Rancangan Tampilan login dan Home

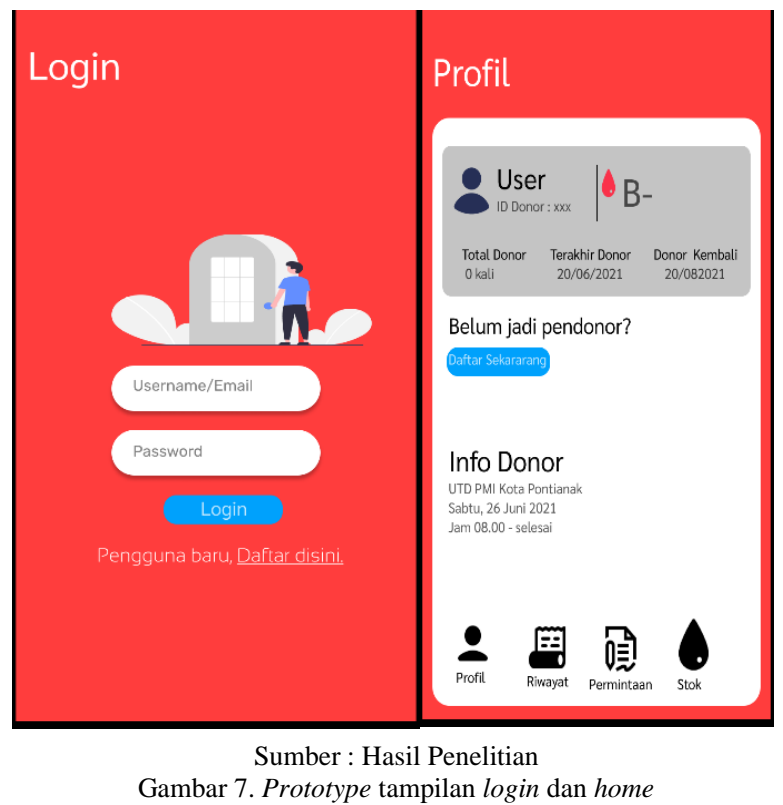


2. Rancangan Tampilan Riwayat dan Permintaan

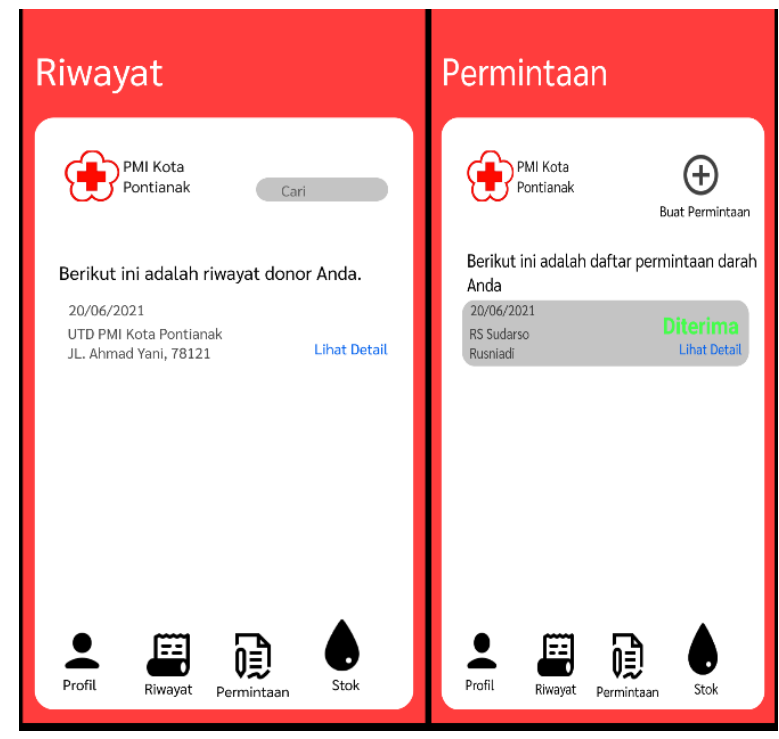

Sumber : Hasil Penelitian

Gambar 8. Prototype riwayat donoh dan permintaan darah

3. Rancangan Rampilan Bagian Administrasi
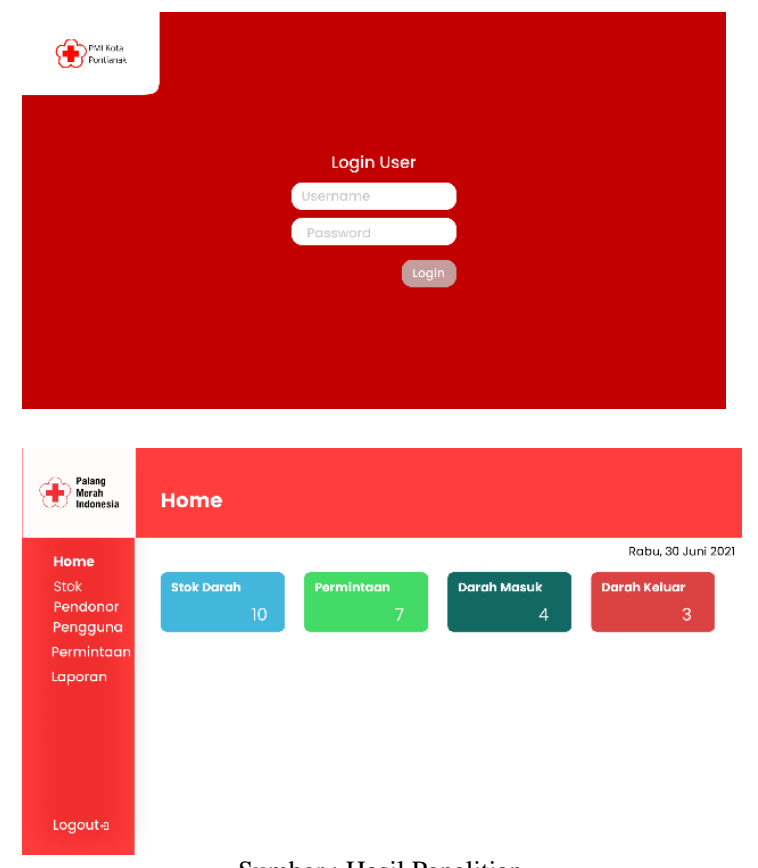

Sumber : Hasil Penelitian

Gambar 9. Prototype tampilan login dan home bagian administrasi
4. Rancangan Tampilan Stok Darah Dan Tabel Donor

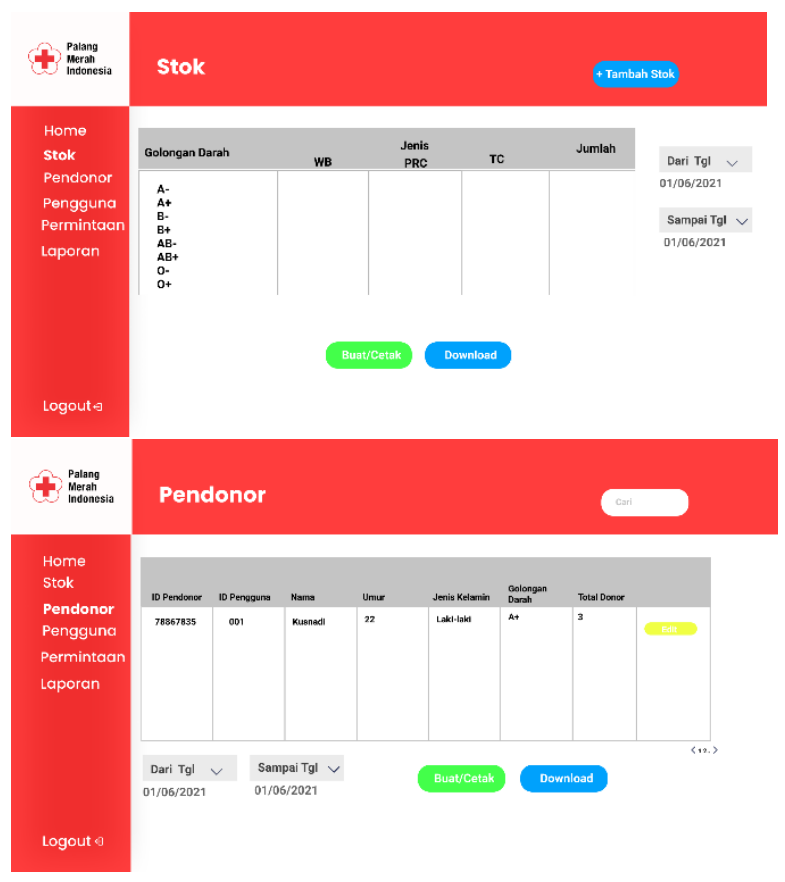

Sumber : Hasil Penelitian (2020)

Gambar 10. Prototype stok darah dan tabel donor

\section{Rancangan Diagram LRS}

Rancangan basis data yang telah dibuat ke dalam model Entity Relationship Diagram (ERD) akan dimodelkan ke dalam bentuk Logical Record Structure (LRS) agar gambaran lebih jelas tentang basis data yang dirancang. Adapun Logical Record Structure (LRS) adalah sebagai berikut.

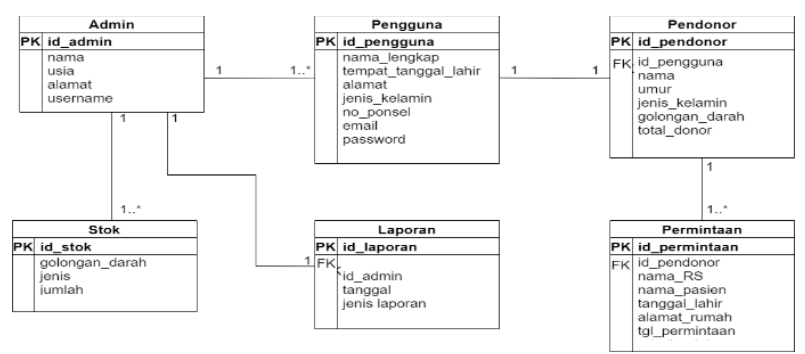

Gambar 11. Local relationship structure (LRS) sistem pelayanan donor dan ketersediaan darah

\section{Diagram Aktivitas}

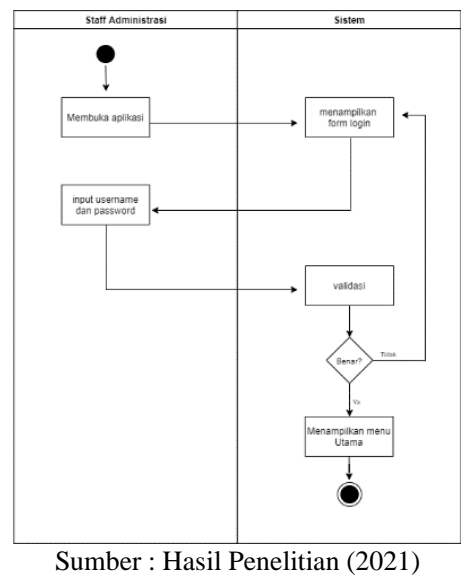

Gambar 12. Diagram aktivitas login staff administrasi 


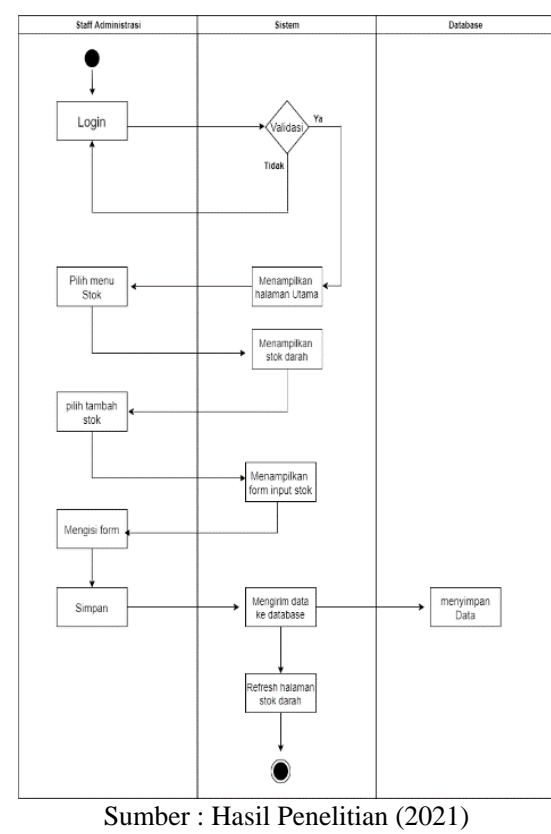

Gambar 13. Diagram aktivitas input stok darah

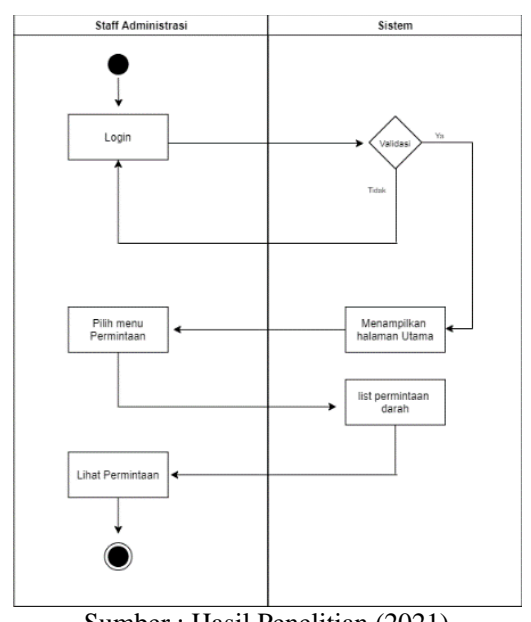

Sumber : Hasil Penelitian (2021)

Gambar 14. Diagram aktivitas melihat permintaan darah

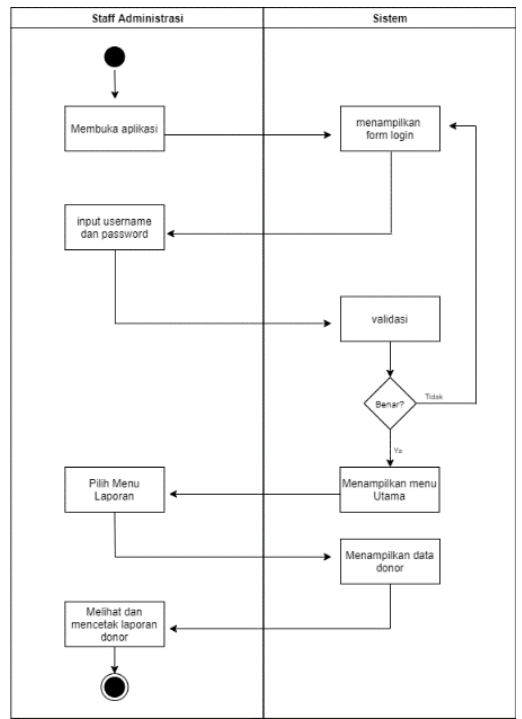

Sumber : Hasil Penelitian (2021)

Gambar 15. Diagram aktivitas lihat dan cetak laoran donor

\section{KESIMPULAN}

Berdasarkan penjelasan yang telah disampaikan sebelumnya mengenai perancangan sistem informasi pelayanan donor dan ketersediaan darah pada PMI Kota Pontianak berbasis mobile, maka dapat ditarik beberapa kesimpulan sebagai berikut. Sistem informasi yang dirancangan dapat membantu masyarakat dalam proses pendaftaran sebagai pendonor secara online sehingga bisa menjadi lebih efisisen. Sistem informasi yang dirancang dapat mengurangi pennumpukan berkas yang disebabkan karena pendataan yang menggunakan media kertas. Sistem informasi yang dirancang dapat mempermudah sistem pelayanan, baik dari pihak instansi maupun masyarakat sebagai pendonor. Dari pihak intansi dapat mengelola data dari pendonor hingga menyampaikan informasi kepada pendonor, sedangkan dari pihak pengguna lebih mudah dalam mendapatkan informasi terkain donor darah.

\section{DAFTAR PUSTAKA}

[1] Y. Firmansyah, R. Maulana, C. Alda Wulandari, J Abdurrahman Saleh No, and K. Barat, "Sistem Informasi Monitoring Siswa Sebagai Media Pengawasan Orang Tua Berbasis Website," Jik, vol. 5, no. 1, 2021.

[2] I. V. Noerhastami R, Sudarwati, "ANALISIS KINERJA KARYAWAN PALANG MERAH INDONESIA (PMI) KOTA," vol. 03, no. 02, pp. 369-375, 2019.

[3] Hutagalung \& Arif, "Rancang Bangun Sistem Informasi Perpustakaan Berbasis Web Pada Smk Citra Negara Depok," J. Chem. Inf. Model., vol. 53, no. 9, pp. 89-99, 2018, doi: 10.1017/CBO9781107415324.004.

[4] A. Mulyanto, "Pengertian Informasi menurut Agus Mulyanto," Sist. Inf. Akunt., 2015.

[5] Krismaji, "Pengertian Informasi menurut krismaji," in Sistem Informasi Akuntansi, 2015.

[6] Puspitawati dan Anggadini, "Bab II Landasan Teori," J. Chem Inf. Model., vol. 53, no. 9, pp. 1689-1699, 2019, doi: 10.1017/CBO9781107415324.004.

[7] Guntoro, "Apa itu Aplikasi Mobile? Inilah Ulasan Lengkapnya !," Badoystudio.Com. 2020.

[8] Manroe, "Pengertian Database dan Contohnya, Fungsi, Manfaat Jenis, dan Komponen," Maxmanroe. 2018

[9] A. Yusron Arif, "Pengertian MySQL, Kelebihan Dan Kekurangan," 2019, 2019

[10] R. Maulana, Y. Firmansyah, and H. Azwan, "Sistem Informasi Pelayanan Donatur Pada Komunitas 1000 Guru Kalbar Berbasis Website," I N F O R M a T I K a, vol. 11, no. 2, p. 24, 2019, doi: 10.36723/juri.v11i2.161.

[11] R. Susanto and A. D. Andriana, "Perbandingan Model Waterfall Dan Prototyping Untuk Pengembangan Sistem Informasi," Maj. Ilm. UNIKOM, vol. 14, no. 1, pp. 41-46, 2016, doi: 10.34010/miu.v14i1.174

[12] D. Purnomo, "Model Prototyping Pada Pengembangan Sistem Informasi," JIMP - J. Inform. Merdeka Pasuruan, vol. 2, no. 2, pp. 54-61, 2017.

[13] R. A. Sukamto and M. Shalahuddin, Kolaborasi Rekayasa Perangkat Lunak Terstruktur dan Berorientasi Objek. Bandung: Informatika, 2015.

[14] A. Hendini, "Pemodelan Uml Sistem Informasi Monitoring Penjualan Dan Stok Barang Barang (Studi Kasus: Distro Zhezha Pontianak)," J. Khatulistiwa Inform., vol. IV, no. 2, pp. $107-$ 116,2016

[15] Y. Firmansyah, R. Maulana, and D. Salindri, "AMIK Dian Cipta Cendikia Bandar Lampung 446 | PROTOTIPE SISTEM INFORMASI PENGOLAHAN ARSIP DATA PEGAWAI PADA DINAS PUPR BERBASIS MOBILE (STUDI KASUS DINAS PEKERJAAN UMUM PROVINSI KALBAR)," $J$ Cendikia, vol. 20, no. 1, pp. 216-9436, 2020.

[16] M. S. Maulana, "PERANCANGAN DAN PENGEMBANGAN APLIKASI WEB PENJUALAN (Studi Kasus: CV. Herson Mitra Solusindo)," J. Khatulistiwa Inform., vol. vol 2, no. no 2, 
pp. $175-183,2014$.

[17] Sugiyono, "Metode Penelitian Kuantitatif Kualitataif dan Kombinasi (Mixed Methods).," J. Chem. Inf. Model., vol. 53, no. 9, p. 240, 2016, doi: 10.1017/CBO9781107415324.004. 